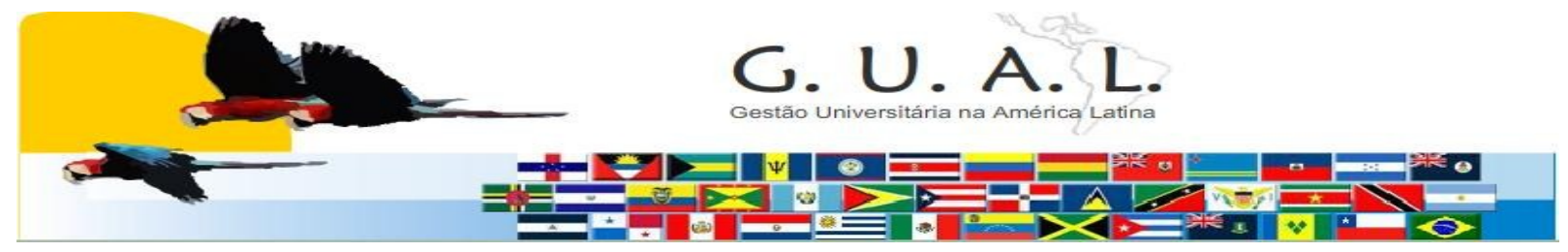

ISSN 1983-4535

\title{
MARCOS REGULATÓRIOS NA EDUCAÇÃO SUPERIOR: A GESTÃO DA UNIVERSIDADE DA REGIÃO DA CAMPANHA - URCAMP FRENTE ÀS EXIGÊNCIAS LEGAIS
}

\author{
GUIDING MARKERS IN HIGHER EDUCATION: AMANAGEMENT OF THE \\ UNIVERSITY OF THE REGION AHEADOF THE CAMPAIGN - URCAMP LEGAL \\ REQUIREMENTS
}

Mirna Susana Viera de Martínez, Doutora Universidade da Região da Campanha - URCAMP mirnaurcamp@hotmail.com

Marilene Vaz Silveira, Mestre Universidade da Região da Campanha - URCAMP marileneurcamp@yahoo.com.br

Recebido em 30/outubro/2011

Aprovado em 18/janeiro/2012

Sistema de Avaliação: Double Blind Review 


\title{
RESUMO
}

O artigo investiga sobre a Gestão da Universidade da Região da Campanha- Urcamp, uma instituição comunitária do Estado do Rio Grande do Sul- Brasil frente às políticas legais que organizam e estruturam a Educação Superior a partir da promulgação da Lei 9.394 de 20 de dezembro de 1996, e as implicações que ocasionaram para as Universidades particulares que precisaram rever seus modelos de gestão e métodos administrativos para serem propulsoras de inovações técnicas, científicas e sociais necessárias ao desenvolvimento regional. Para isso, foi feita uma análise dos documentos legais da Instituição (PDI, PPC), resultados das avaliações in loco feitas por avaliadores externos para reconhecimento e avaliação dos cursos de graduação, resultados do desempenho dos alunos no ENADE e resultados da avaliação interna da Universidade (CPA). Após a análise documental ser possível apontar propostas de soluções para as fragilidades encontradas. Podendo indicar como conclusões provisórias a necessidade de uma gestão compartilhada que lute cada vez mais pelo desenvolvimento de um ensino de qualidade na IES, incentivando o comprometimento, a capacitação e formação continuada dos docentes e corpo técnico administrativo,assim como, a implementação de estratégias de realinhamento da gestão.

Palavras-chave: Gestão universitária. Marcos legais. Avaliação externa.

\begin{abstract}
The article investigates the Management of University of the Campaign-URCAMP, a Community institution of the State of Rio Grande do Sul-Brazil face the legal policies that organize and structure the Higher Education from the enactment of Law 9394 of 20 December 1996, and the implications that led to private universities that needed to review their governance and administrative arrangements to be drivers of technical innovation, scientific and social conditions necessary for regional development. For this purpose an analysis of legal documents of the Institution (PDI, PPP), results of on-site assessments made by external evaluators for recognition and evaluation of graduate programs, results of student performance in ENADE and results of internal evaluation of the University (CPA). After the analysis of documents to be possible to identify proposed solutions to the weaknesses found. Provisional findings may indicate how the need for a shared management to fight more for the development of a quality education in the IES, encouraging commitment, training and continuing education of teachers and administrative staff, as well as the implementation of strategies realignment of management.
\end{abstract}

Keywords: University management. Legal. External evaluation. 


\section{INTRODUÇÃO}

As autoras deste artigo trabalham por longo tempo na IES e sentiram a necessidade de analisar e investigar as dificuldades enfrentadas pela universidade para adaptar-se às mudanças da Legislação Educacional Brasileira, desde a promulgação da Lei 9.394 de 1996. Essa caminhada despertou em nós o interesse em conhecer melhor, por meio de uma abordagem científica, a realidade na área da gestão da URCAMP.

Este artigo analisa através de uma pesquisa documental os pontos fortes e as carências da Instituição perante os pareceres emitidos por avaliadores externos in loco dos cursos de graduação, assim como, análise de resultados obtidos pelos alunos no Exame Nacional de Cursos - ENADE, resultados da avaliação interna - CPA, para após apresentar as possibilidades de saída para a Instituição no que se refere aos focos que a Gestão da IES deve apontar para atender as demandas da comunidade educativa.

De acordo com a temática analisada cabe esclarecer que as autoras deste artigo passaram a exercer função de gestão na IES com a eleição no final de 2010 , da reitora e vicereitor.

Essa equipe gestora propôs um plano de recuperação para a instituição com a proposta de gestão compartilhada e transparência administrativa, já que a instituição apresentava sérios problemas econômicos de endividamento e prestes a enfrentar uma avaliação externa para Recredenciamento da Instituição como Universidade.

Um dos fatores que marcam o decréscimo no número de alunos foi a criação de novas Instituições Públicas e gratuitas em todos os Municípios de atuação desta universidade. Por isso, é necessário rever as estratégias que a gestão deve perseguir constantemente para ajustarse às exigências legais dos órgãos reguladores das políticas da Educação Superior.

\section{DESENVOLVIMENTO}

\subsection{Contextualização da IES}

Com base nos documentos legais da IES acredita-se ser importante uma contextualização e caracterização do perfil institucional da Urcamp, para após confrontar com os marcos legais, pois concordamos com a afirmação extraída de documentos norteadores que colocam que para que o País seja desenvolvido e independente precisa de um forte sistema de educação superior. 
A URCAMP, universidade comunitária com uma área de abrangência em seis municípios da fronteira oeste do Rio Grande do SUL, tendo sua sede em no Município de Bagé, conhecida como a "Rainha da Fronteira", está localizada na fronteira do Rio Grande do SUL a $60 \mathrm{~km}$ do Uruguai e constitui-se no caminho mais curto entre Porto Alegre e Montevidéu (capital do Uruguai). Por sua posição geográfica, desempenhou importante na história do Estado desde o tempo do Império.

A Universidade da Região da Campanha possui como base de atuação a pesquisa tecnológica e aplicada tem em sua origem a própria constituição da Educação Superior em Bagé, que se iniciou em 1953 com a criação da Faculdade de Ciências Econômicas na época mantida pela Associação de Cultura Técnica e Econômica. Em 1955, surge a Faculdade Católica de Filosofia, Ciências e Letras, como extensão da Universidade Católica de Pelotas, sendo que havia na época um convênio com o Instituto Municipal de Belas Artes. Em 1969 ocorreu a integração de todos os cursos superiores existentes e originou a criação da Fundação Universidade de Bagé - FUNBA.

Em 1986 foi aprovado o projeto de transformação das Faculdades Unidas de Bagé em universidade, pelo então Conselho Federal de Educação, que foi reconhecida como Universidade da Região da Campanha - URCAMP, resultando na Portaria ministerial $\mathrm{n}^{\mathrm{o}}$ 052, de 16 de fevereiro de 1989.

O projeto aprovado, entretanto, manteve a forma de escolha do Reitor, vinculado ao processo eleitoral do Conselho Diretor da Fundação Attila Taborda - FAT-, como mantenedora, Em 2004, por meio de uma alteração estatutária, foram convocadas as primeiras eleições para o novo Conselho Diretor da FAT e o seu presidente. A constituição da FAT além de desmembrar a Presidência da Reitoria, aumentou as vagas para a composição do referido Conselho.

A alteração estatutária da Fundação mantenedora implicou em:

- separação definitiva das administrações das duas instituições, de maneira que a figura do reitor da Universidade deixou de corresponder ao de presidente da Fundação. O reitor apenas participa do conselho Diretor da Fundação;

- aumento do número de integrantes do Conselho Diretor, que antes era de 21 membros, passou para 42, com a efetiva participação do poder Público dos oito Prefeitos Municipais dos Municípios de: Bagé, Alegrete, Caçapava do Sul, Dom Pedrito, Itaqui, Sant'Ana do Livramento, São Gabriel e São Borja, sendo estes os locais onde a universidade faz-se representar através de seus Campi. Além destes, representações dos docentes, funcionários e alunos, 
dos Sindicatos das categorias de professores e funcionários juntamente com representantes da comunidade integram o Colegiado. Outra alteração de importante significado é a disposição estatutária que não permite mais de uma reeleição consecutiva da presidência do Conselho e prevê a renovação, cada quadriênio, de 1/3 dos integrantes do colegiado.

No âmbito do ensino de graduação a URCAMP disponibiliza em 59 cursos em funcionamento em 2011/02, um total de 5.809 estudantes, assim distribuídos por Campus e por Centros de Ciências que compõem as áreas de atuação acadêmica:

TABELA 1 Estudantes matriculados por campus

\begin{tabular}{|c|c|}
\hline Campus & $N^{o}$ de Estudantes Matriculados em 2011/02 \\
\hline Bagé & 2.636 \\
\hline Alegrete & 901 \\
\hline São Gabriel & 669 \\
\hline Sant'ana do Livramento & 648 \\
\hline São Borja e Itaqui & 389 \\
\hline Caçapava do Sul & 352 \\
\hline Dom Pedrito & 214 \\
\hline Total & 5.809 \\
\hline
\end{tabular}

TABELA 2 Estudantes matriculados por Centro de Ciências

\begin{tabular}{lc}
\multicolumn{1}{c}{ Centro de Ciências } & $N^{\boldsymbol{o}}$ de Estudantes Matriculados em 2011/02 \\
Economia e Informática & 1.786 \\
Jurídicas & 1.470 \\
Educação, Comunicação e Artes & 1.051 \\
Rurais & 624 \\
Saúde & 519 \\
Exatas e Ambientais & 359 \\
\hline Total & $\mathbf{5 . 8 0 9}$ \\
\hline
\end{tabular}

Fonte: PDI -URCAMP em construção, 2012-2017

No âmbito das atividades extensivas, a URCAMP, além de ser multicampi, com uma lógica abrangência regional, presta vários serviços às comunidades, por meio de atividades extensivas, filantrópicas e que se destacam o Jornal Minuano, em seu XVII ano de edição, realizou sua reformulação gráfica e editorial a partir do ano 2000. O Jornal MINUANO vem oferecendo ao mercado local e à própria produção jornalística um ritmo acentuado de mudanças e modernizações. O principal objetivo do diário que integra a Fundação Attila Taborda é a oferta de informação, a divulgação cultural e artística e a garantia de meios democráticos de acesso às notícias e opiniões, com o contínuo dever de fazer melhor a cada dia da semana, e o Hospital Universitário, uma entidade de caráter filantrópico, que atende ao Sistema Único de Saúde (SUS), particular e convênios, dentre eles: IPE, Unimed, CABERG, 
CASSI. O hospital foi construído na década de quarenta pelo então Dr. Mário Amaral Araújo, o qual em 1978 foi adquirido pela FAT-FunBa (Fundação Attila Taborda - Faculdades Unidas de Bagé), passando a chamar-se Casa de Saúde FAT-FUNBA.

Em 1993, passou a Hospital Universitário - URCAMP (HU). Recentemente o Conselho Diretor da FAT aprovou uma nova denominação para a instituição hospitalar: Hospital Universitário Dr. Mário Araújo. O hospital conta atualmente com 22 leitos pediátricos, 67 clínicos, 12 cirúrgicos e 9 de Tratamento Intensivo, presta serviços variados à comunidade, atendendo Bagé e municípios vizinhos, sendo enquadrado como Hospital Microregional no Sistema Hierarquizado de Saúde Pública.

O hospital proporciona campo de estágios curriculares e extracurriculares para acadêmicos do Centro de Ciências da Saúde (CCS) da URCAMP, dos cursos de Fisioterapia, Enfermagem, Psicologia, Farmácia, Nutrição, sendo estes supervisionados por docentes do Centro de Ciências da Saúde, criando assim campo de pesquisa em diversas áreas da saúde. Importante conscientização para com história e preservação cultural patrimonial se destacam: o Museu Dom Diogo de Souza, que possui grande acervo e as atividades dele promovem e estimulam as manifestações culturais da região, resgatam a cultura do homem da campanha e o reflexo dessa cultura através da história. Durante todo o ano são realizadas exposições, congressos, concertos, atividades artísticas, conferências, entre outros eventos. Paralelo ao trabalho de difundir e manter a memória da história de Bagé e localidades próximas, são produzidos e divulgados vídeos e mostras fotográficas e mantidas coleções completas de jornais de várias épocas.

No ano de 2005 o museu Dom Diogo de Souza recebeu incentivo da Petrobrás, através da Lei Rouanet, que investiu na reforma do prédio, bem como na construção de um anfiteatro. Também ressalta-se, o Museu da Gravura Brasileira, possuidor de acervo de obras dos artistas bageenses, brasileiros e de outros países Mantém mostras permanentes para visitação pública de representações do Uruguai, Argentina, Chile, estudantes de Bagé e de outras regiões. O Museu Patrício Corrêa da Câmara localizado junto às fundações do Forte de Santa Tecla (1773-1776) expõe variado material, encontrado em escavações arqueológicas executadas na área dessa fortificação espanhola. Dispõe ainda de exposições de diversos objetos que fazem parte da história do gaúcho da fronteira. Além destes, também em Sant'ana do Livramento, temos o Museu ASPES/Urcamp, aberto à comunidade acadêmica e comunidade em geral, recebe visitas programadas. Em seu acervo estão várias obras nacionais importantes como "O Cangaceiro" de autoria de Cândido Portinari. Na Pinacoteca há, entre outras, obras de 
Rodolfo Amoedo, Castagnetto, Di Cavalcanti, Osvaldo Goeldi, Lasar Segall, Portinari, Djanira e Tarsila do Amaral.

A partir da citação de alguns exemplos de inserção à sociedade, a Extensão Universitária na URCAMP, considera-se em conformidade com sua missão, definindo-se como uma das funções sociais da Universidade, resultando uma "relação transformadora entre Universidade e Sociedade".

Como prática acadêmica indispensável à formação do aluno e à qualificação do professor e no intercâmbio com a sociedade, proporciona uma relação interativa entre as diferentes áreas do conhecimento e os múltiplos segmentos sociais.

Portanto, na URCAMP, a extensão universitária é compreendida como estratégia para promover a articulação das diferentes áreas de conhecimento com os diversos segmentos da sociedade, levando em consideração a realidade social, numa perspectiva transformadora. Por outro lado, poderá ser assumida como fonte de ensino e aprendizagem proporcionando aos docentes, técnicos científicos, administrativos e discentes, sua permanente capacitação.

No âmbito da pesquisa acadêmica, destaca-se que a URCAMP vinha desenvolvendo ações isoladas de pesquisa, em todos os campi, por meio de pesquisadores individuais, fato que gerou a criação de mais de 80 núcleos de pesquisa, orientados para as disciplinas da graduação. Como consequências desse esforço de pesquisa, associado aos programas e projetos de extensão, foram implantados dois institutos: o Instituto de Pesquisas Ambientais e Energias (IPAE), criado em 1988 e o Instituto Biotecnológico de Reprodução Vegetal (INTEC), criado em 1997.

Em 2011, com a retomada da implantação institucional da Pesquisa, a URCAMP mantém o registro de um grupo de pesquisa, junto ao Diretório de Grupos de Pesquisa do CNPq, e prevê a ampliação de cinco novos grupos, considerando o plano de ampliação e consolidação da Pós-graduação Stricto sensu.

Destaca-se ainda, a partir dos resultados das pesquisas desenvolvidas nos institutos (IPAE e INTEC) e da retomada da Pesquisa Institucional as ações objetivas à implantação da Pós-graduação Stricto Sensu, com o encaminhamento, em 2011, do Mestrado Profissional em Sistemas Produtivos do Pampa e do Mestrado em Qualidade Ambiental, previsto para o ano de 2012 .

Também em 2011, a URCAMP, a partir de seus campi regionais, consciente da importância da Pesquisa institucional na relação com o Ensino e a Extensão, retoma a definição de Linhas Institucionais de Pesquisa, Tecnologia e Ação Comunitária, definidas a 
partir da demanda regional, que concentram objetos e temas de investigação científica e tecnológica e que orientam a implantação de programas e projetos de extensão e de ação socioeconômica. A finalidade das Linhas é servir de referência para o avanço do conhecimento científico, cultural e tecnológico, a formação de alunos de graduação e de pósgraduação e para o desenvolvimento sustentável da região de abrangência da URCAMP.

Em relação ao Pós-graduação Lato Sensu, destaca-se a contínua e orientada ação da URCAMP na formação continuada dos egressos e da comunidade externa e interna, a partir da implantação de cursos planejados no calendário acadêmico da universidade nos centros acadêmicos, na última década.

Toda mudança conceitual em termos de gestão da Universidade é um processo lento para atender os critérios de exigência do MEC para o Ensino de Graduação e Pós- Graduação. Para isso devemos levar em consideração: as dificuldades que a universidade enfrenta, o nível elevado dos critérios do MEC para uma Universidade Comunitária, os impactos das propostas sobre a realidade vivida pela organização conforme o nível de amadurecimento das mesmas e a vontade dos indivíduos envolvidos em torná-las bem sucedidas, a inovação metodológica e tecnológica que a instituição precisa para atender as exigências do mundo contemporâneo.

Por isso busca-se investigar se a Universidade da Região da Campanha - URCAMP poderá estar preparada para atingir o referencial mínimo de qualidade.

Franco (2002) entende que, atualmente, as condições para superar práticas tradicionais de gestão e promover um desenvolvimento qualitativo da educação superior estão na implementação de modelos de gestão profissional e inovadora. A implementação desses modelos tende a exigir um realinhamento de estratégias de ação das IES em busca do cumprimento de sua missão e do atendimento à demanda de alunos para a educação superior.

Foi utilizada a pesquisa documental que se fundamenta no uso de documentos que devem ser apreciados e valorizados. Pois, a riqueza de informações que deles podemos extrair e resgatar justifica o seu uso em várias áreas das Ciências Humanas e Sociais porque possibilita ampliar o entendimento de objetos cuja compreensão necessita de contextualização histórica e sociocultural.

Ao discutir o conceito e o papel da metodologia da pesquisa documental imprime um enfoque plural para a questão: “a metodologia inclui as concepções teóricas de abordagem, o conjunto de técnicas que possibilitam a apreensão da realidade e também o potencial criativo do pesquisador" (MINAYO, 2008: 22). Portanto, a pesquisa documental é um procedimento 
que se utiliza de métodos e técnicas para a apreensão, compreensão e análise de documentos dos mais variados tipos.

Para isso, partiu-se primeiramente da análise do PDI anterior da Instituição e o que estamos elaborando 2012-2017, o documento orientador para as visitas in loco enfatizando: Organização Didático-Pedagógica, Corpo docente, Instalações Físicas, resultados do desempenho dos alunos no ENADE, PPC do Curso.

Após o levantamento de documentos, junto ao Setor de Planejamento da URCAMP, com os resultados dos pareceres dos avaliadores, e notas do Enade (CPC) foi organizado o quadro a seguir que apresenta em dados quantitativos a situação dos Cursos de Graduação que obtiveram nota inferiores a 3 e portanto necessitavam avaliações in loco.

\begin{tabular}{|c|c|c|c|}
\hline CURSOS & NOTA ENADE CPC & $\begin{array}{c}\text { RENOVAÇÃO DE } \\
\text { RECONHECIMENTO } \\
\text { DE CURSO }\end{array}$ & $\begin{array}{l}\text { DIMENSÃO } \\
\text { CONCEITO* }\end{array}$ \\
\hline $\begin{array}{l}\text { Administração- } \\
\text { Alegrete }\end{array}$ & 2 & $\begin{array}{l}\text { Avaliadores: nota } 3 \\
\text { MEC: nota2 }\end{array}$ & $\begin{array}{l}\text { Dimensão } 1 \text { nota } 3 \\
\text { Dimensão } 2 \text { nota } 2 \\
\text { Dimensão } 3 \text { nota } 3\end{array}$ \\
\hline Pedagogia - SB & ? & 3 & $\begin{array}{l}\text { Dimensão } 1 \text { nota } 1 \\
\text { Dimensão } 2 \text { nota } 1 \\
\text { Dimensão } 3 \text { nota } 1\end{array}$ \\
\hline Pedagogia - SB & 2 & 3 & $\begin{array}{l}\text { Dimensão } 1 \text { nota } 4 \\
\text { Dimensão } 2 \text { nota } 3 \\
\text { Dimensão } 3 \text { nota } 3\end{array}$ \\
\hline C.Biológicas - SB & $\mathrm{SC}$ & 3 & $\begin{array}{l}\text { Dimensão } 1 \text { nota } 3 \\
\text { Dimensão } 2 \text { nota } 2 \\
\text { Dimensão } 3 \text { nota } 3\end{array}$ \\
\hline Matemática - SB & 2 & 3 & $\begin{array}{l}\text { Dimensão } 1 \text { nota } 3 \\
\text { Dimensão } 2 \text { nota } 4 \\
\text { Dimensão } 3 \text { nota } 3\end{array}$ \\
\hline C.Contábeis -SB & 2 & 2 & $\begin{array}{l}\text { Dimensão } 1 \text { nota } 2 \\
\text { Dimensão } 2 \text { nota } 2 \\
\text { Dimensão } 3 \text { nota } 2\end{array}$ \\
\hline História - SB & $\mathrm{SC}$ & 3 & $\begin{array}{l}\text { Dimensão } 1 \text { nota } 3 \\
\text { Dimensão } 2 \text { nota } 2 \\
\text { Dimensão } 3 \text { nota } 3 \\
\end{array}$ \\
\hline C.Biológicas - SG & 2 & 1 & $\begin{array}{l}\text { Dimensão } 1 \text { nota } 2 \\
\text { Dimensão } 2 \text { nota } 1 \\
\text { Dimensão } 3 \text { nota } 1\end{array}$ \\
\hline C.Contábeis - SG & 2 & 3 & $\begin{array}{l}\text { Dimensão } 1 \text { nota } 3 \\
\text { Dimensão } 2 \text { nota } 3 \\
\text { Dimensão } 3 \text { nota } 2\end{array}$ \\
\hline Direito - SG & 2 & 3 & $\begin{array}{l}\text { Dimensão } 1 \text { nota } 3 \\
\text { Dimensão } 2 \text { nota } 2 \\
\text { Dimensão } 3 \text { nota } 3\end{array}$ \\
\hline Letras - SG & $\mathrm{SC}$ & 2 & Dimensão 1 nota 2 \\
\hline
\end{tabular}




\begin{tabular}{|c|c|c|c|}
\hline & & & $\begin{array}{l}\text { Dimensão } 2 \text { nota } 2 \\
\text { Dimensão } 3 \text { nota } 2\end{array}$ \\
\hline C.Sociais - Bagé & $\mathrm{SC}$ & 3 & $\begin{array}{l}\text { Dimensão } 1 \text { nota } 3 \\
\text { Dimensão } 2 \text { nota } 4 \\
\text { Dimensão } 3 \text { nota } 2\end{array}$ \\
\hline Farmácia-Bagé & 2 & 2 & $\begin{array}{l}\text { Dimensão } 1 \text { nota } 2 \\
\text { Dimensão } 2 \text { nota } 2 \\
\text { Dimensão } 3 \text { nota } 3\end{array}$ \\
\hline FisioterapiA - Bagé & & Em diligência & $\begin{array}{l}\text { Dimensão } 1 \text { nota } 3 \\
\text { Dimensão } 2 \text { nota } 2 \\
\text { Dimensão } 3 \text { nota } 3\end{array}$ \\
\hline Fisioterapia - Bagé & 2 & 3 & $\begin{array}{l}\text { Dimensão } 1 \text { nota } 3 \\
\text { Dimensão } 2 \text { nota } 2 \\
\text { Dimensão } 3 \text { nota } 3\end{array}$ \\
\hline Nutrição - Bagé & 2 & 3 & $\begin{array}{l}\text { Dimensão } 1 \text { nota } 3 \\
\text { Dimensão } 2 \text { nota } 2 \\
\text { Dimensão } 3 \text { nota } 3\end{array}$ \\
\hline Matemática - Bagé & 2 & 3 & $\begin{array}{l}\text { Dimensão } 1 \text { nota } 4 \\
\text { Dimensão } 2 \text { nota } 3 \\
\text { Dimensão } 3 \text { nota } 3\end{array}$ \\
\hline $\begin{array}{c}\text { Gestão da Tecnologia } \\
\text { da Informação - } \\
\text { Caçapava }\end{array}$ & $\begin{array}{c}\text { Reconhecimento do } \\
\text { Curso }\end{array}$ & 3 & $\begin{array}{l}\text { Dimensão } 1 \text { nota } 3 \\
\text { Dimensão } 2 \text { nota } 4 \\
\text { Dimensão } 3 \text { nota } 3 \\
\end{array}$ \\
\hline $\begin{array}{l}\text { C.Biológicas - } \\
\text { Caçapava }\end{array}$ & $\mathrm{SC}$ & 2 & $\begin{array}{l}\text { Dimensão } 1 \text { nota } 3 \\
\text { Dimensão } 2 \text { nota } 2 \\
\text { Dimensão } 3 \text { nota } 2\end{array}$ \\
\hline Pedagoagia - DP & $\mathrm{SC}$ & 1 & $\begin{array}{l}\text { Dimensão } 1 \text { nota } 1 \\
\text { Dimensão } 2 \text { nota } 1 \\
\text { Dimensão } 3 \text { nota } 1\end{array}$ \\
\hline Informática - SL & 2 & 2 & $\begin{array}{l}\text { Dimensão } 1 \text { nota } 2 \\
\text { Dimensão } 2 \text { nota } 2 \\
\text { Dimensão } 3 \text { nota } 2\end{array}$ \\
\hline Direito - SL & 2 & 2 & $\begin{array}{l}\text { Dimensão } 1 \text { nota } 3 \\
\text { Dimensão } 2 \text { nota } 1 \\
\text { Dimensão } 3 \text { nota } 2\end{array}$ \\
\hline
\end{tabular}

QUADRO 1 Nota ENADE e Avaliações in loco dos Cursos de Graduação da URCAMP *1 - Organização Didático- Pedagógica; 2 - Corpo docente; 3 - Instalações Físicas

Fonte: primária, outubro de 2011.

Observa-se pelo quadro acima o quanto precisamos de Gestão em nossas IES, pois a URCAMP demonstra isto ao receber as visitas in loco, organiza seus cursos e consegue ser aprovada em 13 das 22 visitas por uma comissão designada pelo MEC.

Percebe-se a fragilidade de alguns Campi Universitários que ao receberem as visitas não conseguem aprovação, pois a gestão entre a Sede e os Campi ainda carece de três grandes atividades segundo (Chandler,1999): Alocação de recursos; monitoração dos recursos alocados; coordenação para a alocação dos recursos atividades estas imprescindíveis a uma boa gestão. 
Decorre uma análise feita a partir de observações pessoais que há necessidade da Urcamp oferecer cursos de capacitação aos gestores dos Campi para um desempenho mais qualificado não só no aspecto administrativo, mas essencialmente pedagógico.

A dimensão dois, corpo docente, é a mais deficitária em todos os relatórios de avaliação, pois a Urcamp não possui programa de strictu sensu, observa-se a falta de um plano de expansão e capacitação ocasionando uma ruptura no processo de fluxo contínuo de formação docente.

Ainda, é possível detectar que a dimensão 3 instalações físicas é deficitária em alguns Campi, sendo o fator da acessibilidade o que mais forte arrasta a nota para baixo nas avaliações de cursos. Por isso a IES necessita implementar ações estratégicas de preparação e motivação dos alunos que nos ciclos avaliativos do ENADE realizam a prova, sendo que, uma nota satisfatória exime uma avaliação in loco.

\section{CONSIDERAÇÕES FINAIS}

É importante que a Gestão da Instituição no seu todo reconsidere a forma de se preparar para as avaliações externas, primando pela excelência acadêmica, tendo como princípio orientador a busca da qualificação do seu corpo docente, tendo como metas o aumento de professores titulados; número de grupos de pesquisa com produção científica significativa de acordo com as exigências nacionais; a integração com a comunidade local e regional em todos os campi e ampliando seus leques de parcerias.

Ainda, na ênfase da formação humana e profissional a IES precisa estimular a formação continuada de professores e técnicos administrativos, pois, os marcos legais apontaram, nas avaliações externas, fragilidades a serem corrigidas.

Por fim, fica claro que o desempenho de uma IES não deve ser medido exclusivamente pelo aspecto financeiro obtido pelas mesmas, mas, pelo grau de eficácia com que suas missões e, consequentemente, seus planos estratégico, para o objetivo fim: ensino, pesquisa e extensão.

Por último, cabe dizer que há necessidade de uma gestão compartilhada com todos, pois é o conjunto agindo proativamente que poderá transformar as velhas práticas de gestão em uma ação oriunda da integração e reconhecimento da comunidade por meio do desempenho superior na avaliação institucional interna e externa. 


\section{REFERÊNCIAS}

BRASIL, Lei de Diretrizes e Bases da Educação Nacional, nº 9.394de20 de dezembro de 1996. MEC

FRANCO, Édison. Funções do coordenador de curso: como construir o coordenador ideal. Brasília: ABMES, 2002.

MINAYO, M.C.S. O desafio do conhecimento: pesquisa qualitativa em saúde. $11^{\mathrm{a}}$ ed. São Paulo, HUCITEC, 2008.

SILVA, Renato. Gestão do ensino superior. Curitiba: Juruá, 2009.

TACHIZAWA, Takeshy. Gestão de instituições de ensino. Rio de Janeiro: Fundação Getúlio Vargas, 1999. 